\title{
ADOÇÃO ÀS PRÁTICAS DE QUALIDADE PELAS CONCESSIONÁRIAS AUTOMOTIVAS SITUADAS EM NATAL/RN.
}

\author{
Jamil Farkat (UFRN, Brasil) farkatt@gmail.com \\ Kleber Sousa (UFRN, Brasil) ksnat@hotmail.com \\ Fernanda Queiroz (UFRN, Brasil) fernandacbpereira@gmail.com \\ Jamerson Viegas Queiroz (UFRN, Brasil) viegasqueiroz@gmail.com \\ Hélio Hekis (UFRN, Brasil) hekis1963@gmail.com
}

Resumo: Este estudo objetivou identificar o nível de adoção das práticas de qualidade e a utilização de sistemas de gestão de qualidade em 22 concessionárias de veículos situadas em Natal/RN. Para tanto a metodologia Survey foi utilizada como instrumento de coleta estruturado em uma escala "Likert" e aplicado aos Gerentes Operacionais de cada organização, possibilitando responder o objetivo proposto. Os resultados demonstraram que 20 concessionárias obtiveram nível de adoção as práticas de qualidade entre quatro "bom" e cinco "muito bom", destas 17 adotam sistemas de gestão da qualidade. Conclui-se que a maioria destas organizações possuem níveis de qualidade satisfatórios, tendo a alta direção comprometida a desenvolver e aplicar políticas de qualidade, realizando melhorias necessárias nos processos, buscando garantir conformidade de seus produtos e aumentar a satisfação de seus clientes. Portanto acredita-se que as concessionárias de Natal/RN estão prontas e capacitadas a oferecer produtos e serviços de qualidade mundial.

Palavras-Chaves: Práticas de qualidade, Sistemas de gestão de qualidade, Concessionárias Automotivas Brasileiras.

Abstract: This study aimed identifies the level of adoption of quality practices and use of quality management systems in 22 automotive dealerships located in Natal/RN. The Survey methodology was used, with a questionnaire based on a Likert scale. This instrument was applied to Operational Managers of each organization, enabling answer both objectives outlined. The results showed that 20 dealers obtained level of adoption practices in quality between 4 "good" and 5 "very good" and 17 of these organizations adopt quality management systems. Concludes that most of these organizations have satisfactory levels of quality, having top management engaged to develop and implement quality policies, making necessary improvements in processes, seeking to ensure compliance of their products and increase customer satisfaction. Therefore it is believed that the automotive dealerships Natal/RN are ready to offer a world class products and services.

KeyWords: Quality Practices, Quality Management Systems, Brazilian Automotive Dealerships 


\section{Introdução}

O Departamento Nacional de Transito Brasileiro afirma que no ano de 2012 foram comercializados 368.285 .400 milhões de veículos leves até setembro (DENATRAN, 2012). Esses números colocam o Brasil em $4^{\circ}$ lugar no ranking das vendas globais, superando importantes centros de consumo como Alemanha e Índia (DYNAMICS, 2012).

O destaque conquistado pelo Brasil em vendas no setor automotivo se deve ao aumento do poder de compra da população brasileira, pela redução da pobreza com o surgimento de uma nova classe média, e também devido a adoção de políticas redutivas de impostos aplicadas aos produtos industrializados, sancionadas pelo Governo Federal. Com esse cenário favorável expande-se a oferta de credito para compra de veículos, onde se estima que até o final de 2012 as instituições financeiras disponibilizem US\$ 99,56 bilhões para o financiamento de automóveis (ANEF, 2012).

Para o MDIC (2012) esses estímulos ao consumo são reflexos da "combinação de políticas sociais inovadoras de distribuição de renda, estabilidade e transparência financeira e política, crescimento sustentável e responsabilidade fiscal que conduziu o Brasil a se firmar entre as maiores economias do planeta do século 21". A consolidação do crescimento econômico brasileiro é também visualizada pela comunidade financeira internacional. A Standard \& Poor's (S\&P), agência americana avaliativa de investimentos, no ano de 2011, elevou a nota de crédito do Brasil de BB- para BBB, esta justificada pela existência de ações governamentais empenhadas na redução de gastos públicos e abertura de espaço para redução de juros, refletindo maior seguridade para realização de investimentos no país (FOLHA, 2011).

Visualizando todo esse potencial econômico relatado, as indústrias automotivas americanas, europeias e principalmente as asiáticas direcionam seus esforços de vendas no Brasil, objetivando conquistar o seu mercado automotivo. Para tanto é preciso que essas organizações promovam estratégias competitivas, que embasadas em práticas de qualidade propiciam notoriedade em meio a um mercado fortemente concorrido. As praticas de qualidade contribuem de forma importante para as organizações se diferenciarem, visto que através do atendimento das necessidades dos consumidores, constituem força competitiva. (PRAJOGO E SOHAL, 2006; FUENTES ET AL 2011).

Neste sentido Crosby (1999) destaca que a qualidade significa cumprir com os requisitos combinados com o cliente. Diante desse conceito, verifica-se que a Concessionária é o ponto final e critico dentro de cadeia de suprimento automotivo, devido ser responsável pela distribuição dos automóveis aos consumidores, bem como pelo processo de manutenção, requerendo total atenção ao 
cliente para interpretação e saneamento de suas necessidades. Por fim a concessionária detém papel chave dentro do processo de desenvolvimento de novos veículos, visto que através de sua gestão informacional é possível apontar a unidade fabril as variações de desempenho observadas, cruciais na efetuação de correções e adaptações a novos projetos de produtos.

Compreendendo todo o contexto anterior, a referida pesquisa objetivou identificar nas concessionárias automotivas de veículos comerciais leves, situadas na cidade do Natal/RN, capital do estado brasileiro do Rio Grande do Norte, Brasil, o nível de adoção as práticas de qualidade, bem como verificar quais destas possuem sistemas formais de gestão da qualidade.

A organização do presente estudo inicia-se com a presente introdução, seguida pela Seção 2, a revisão literária, na qual destaca conceitos teóricos relevantes a pesquisa. Em continuidade a Seção 3, métodos, na qual se especifica a metodologia de pesquisa utilizada. Posteriormente, na Seção 4 podem ser observados os resultados encontrados, e logo em seguida, na Seção 5, encontram-se as considerações finais e por fim, na Seção referências, são apresentadas as bibliografias consultadas.

\section{Revisão literária}

\subsection{Qualidade: conceito e evolução}

Desde 1950, o movimento da Qualidade Total vem propiciando revoluções nas organizações. Diversos autores desenvolveram pesquisas nessa área, o que proporcionou um avanço nos conceitos e nas aplicações sobre o tema "qualidade". O conceito de qualidade pode sofrer variações, devido o enfoque diferenciado analisado por cada autor.

Juran (1990) afirma que a Qualidade é ausência de deficiências, ou seja, quanto menos defeitos, melhor a qualidade. Para Crosby (1990), qualidade é a conformidade do produto com os requisitos ou especificações estabelecidos. Já para Deming (1990), qualidade é a capacidade de atender, e se possível, exceder as expectativas do consumidor.

De acordo com a ISO 9000 (2008), a qualidade é descrita como um conjunto de propriedades e características de um produto, processo ou serviço, que the fornecem a capacidade de satisfazer as necessidades explícitas ou implícitas das pessoas.

A evolução é constatada quando se percebe que o foco da "Qualidade" amplia-se, deixando de visualizar somente o escopo do produto e sua conformidade técnica, para evidenciar a relação do uso do produto com o suprimento das necessidades do consumidor. Neste sentido Srivastav (2010), afirma que nos dias de hoje, a Qualidade dos produtos e serviços é essencial para a realização da satisfação do cliente.

Assim sendo, esta busca pela qualidade e excelência, tornou-se um objetivo estratégico de muitas organizações globais. Fuentes et al (2011) conclui que a "Qualidade tornou-se uma prioridade competitiva". 


\subsection{Gestão da Qualidade}

Garvin (1992) afirma que o surgimento da gestão da qualidade está associado a diversos fatores, entretanto duas situações destacam-se. Primeiro o aumento das exigências dos consumidores, e segundo a chegada de produtos importados com preços mais acessíveis ao mercado. A importação manufatureira decorrente da produção industrial japonesa teve como alvo o mercado norte-americano na década de 1990. Essa produção com qualidade superior e preços reduzidos foi possibilitada devido os japoneses deterem práticas de gestão concentradas na busca pela qualidade, incorporando tal ato como filosofia, alcançando a excelência e consequentemente a competitividade.

O modelo japonês de gestão, baseado na gestão da qualidade total (TQM), no just-in-time (JIT), na manutenção produtiva total (TPM), e na engenharia simultânea, aliado a sua a estrutura organizacional horizontal, proporcionou a prosperidade a suas indústrias, semeando sua sobrevivência global, diante de um mercado altamente competitivo (ANN ET $\mathrm{AL}, 2011)$.

A exemplo disto, conhecer o impacto da adoção das práticas de Gestão da Qualidade (QM) sobre os resultados das organizações atraeem a atenção dos pesquisadores e vem tornando-se uma linha de pesquisa bastante difundida (FUENTES ET AL, 2011).

Slack et al. (2002), compreendem a gestão da qualidade total como uma filosofia, forma de pensar e trabalhar, preocupada com o atendimento das necessidades e expectativas dos clientes, orientando foco da qualidade para todas as operações desenvolvidas na organização. Nesta visão observa-se a importância dada para a gestão dos processos, fazendo ressalvas que a qualidade deve ser avaliada, fase a fase, e que todos precisam estar envolvidos e comprometidos na busca da qualidade.

As organizações são formadas por pessoas e estas são o bem mais valioso, devido serem reconhecidas como fontes inesgotáveis de conhecimento e possuidoras decapacidade elevada para realização e transformação do ambiente inserido. Situações em que os colaboradores são mais participativos e cooperativos, favorecem a obtenção de melhores resultados aliado a implantação das práticas da Gestão da Qualidade Total. Validando a ideia anterior, estudos realizados demonstraram que a cultura organizacional deve ser avaliada e trabalhada para proporcionar um ambiente propício a implementação das práticas de Gestão da Qualidade Total (BAIRD ET AL, 2011).

Uma cultura favorável a Gestão da Qualidade Total é aquela que consegue envolver as pessoas nas atividades, promove a sensação de orgulho na realização das tarefas, afasta o medo, permite participação das pessoas na gestão, incentiva o desenvolvimento da liderança e promove orientação de longo prazo entre os membros da organização (IRANI ET $\mathrm{AL}, 2004)$.

Portanto, a gestão da qualidade total - TQM - é mostrada como um meio eficaz para a implantação de uma estratégia com objetivo da 
diferenciação competitiva (PRAJOGO E SOHAL, 2006).

Fuentes et al (2011), concorda que as organizações mais inovadoras são mais capazes de implantar a gestão da qualidade total, e assim buscar continuamenteformas de melhoraros processos de trabalho, incrementando suacapacidade de fornecerprodutos e serviços com qualidade mundial.

\subsection{Sistemas de Gestão da Qualidade e suas práticas}

Os esforços de qualquer organização para o alcance de melhorias continuas de qualidade devem envolver a aplicação sistemas de qualidade e práticas relacionadas. Tais esforços são importantes para melhoria da qualidade dos produtos e/ou serviços aumentando o desempenho empresarial (LEE, 2012).

A ISO 9000 (2008) define o sistema de gestão da qualidade, como sendo um "Sistema de gestão (sistema para estabelecer política e objetivos, e para atingir estes objetivos) para dirigir e controlar uma organização (grupo de instalações e pessoas com um conjunto de responsabilidades, autoridades e relações), no que diz respeito à qualidade (grau no qual um conjunto de características inerentes satisfaz a requisitos)".

Prajogo (2011) destaca que o objetivo das normas ISO 9000 é garantir que uma empresa certificada mantenha um sistema de gestão de qualidade que lhe permita cumprir os seus padrões de qualidade publicados, em relação aos processos e atividades para a entrega de bens e serviços.

Srivastav (2010) afirma que a implantação adequada da IS0 9000 proporcionará as organizações um maior envolvimento dos trabalhadores na resolução dos problemas, fortalecerá o espírito de equipe, aumentará a satisfação das pessoas no trabalho e contribuirá para melhorar na cultura organizacional, assim favorecendo a inovação as mudanças quando necessário. Assim sendo, quando se implantam sistemas de gestão da qualidade, como a ISO 9000, por exemplo, espera-se uma melhoria considerável na qualidade dos produtos, serviços, processos e na satisfação dos clientes. E isto contribuirá para a melhoria da imagem desta empresa junto aos consumidores, difereciando-a de outras organizações concorrentes, já que a qualidade cria uma vantagem competitiva através da fidelização de clientes, e ainda diminuindo a sensibilidade destes ao fator preço (PRAJOGO E SOHAL, 2006).

Entretanto, para haver uma implementação bem-sucedida de gestão da qualidade, é necessário que várias práticas cotidianas sejam conduzidas, como a gestão de processos, foco no cliente, envolvimento de qualidade, fornecimento e atividade em pequenos grupos pequenos (FLYNN ET AL, 1995).

Assim, neste sentido o corpo executivo, isto é a liderança da organização, exerce um importante papel para desenvolver e implantar as estratégias que possam conduzir as organizações ao sucesso. Garvin (1992) evidencia que o comprometimento da alta 
gerência, através de sua conscientização para a qualidade, servirá como efeito multiplicador para a legitimação do processo como um todo. Assim é preciso que os executivos, que compõem a alta gestão das organizações, assumam o compromisso de implantar a gestão da qualidade, consolidando práticas de qualidade nestas organizações.

Segundo Ilkay e Aslan (2011), as práticas de qualidade englobam 6 fatores, os quais são: 1 liderança pela alta gerência, 2 - orientação ao cliente, 3 - processos dos sistemas de qualidade, 4 - aplicações dos recursos humanos, 5 - relações com fornecedores, 6 controle de processos e melhoria. O primeiro fator aborda questões relevantes a ações administrativas para geração, aplicação e controle de políticas de qualidade. O segundo refere-se aos esforços direcionados para identificação e suprimento das necessidades dos consumidores. $O$ terceiro aborda a elaboração de processos, munidos de ferramentas que auxiliem o controle de qualidade. O quarto trabalha na aplicação otimizada dos recursos humanos em prol da qualidade. O quinto busca padronizar processo de escolha de fornecedores, determinando critérios de seleção, bem como elaborar processos para inspeção dos materiais adquiridos. Por fim, o sexto fator promove a criação e aplicação de métodos para medição e controle dos processos, objetivando alcançar padrões de melhoria continua.

As empresas com maior desempenho financeiro e operacional por empregado se destacam por possuírem apoio da alta gestão e por desenvolverem estratégias de qualidade voltadas para os clientes (FUENTES ET AL, 2011).

Estudos realizados demonstram que a falta de envolvimento da gestão de topo, isto é o corpo executivo das organizações, é considerado o principal obstáculo enfrentado pelas empresas durante a implementação da ISO 9001 e a sua certificação (SAMPAIO ET AL, 2009).

\subsection{Sistema de Gestão de Qualidade como diferencial competitivo}

Powell (1995) confirma que existe uma relação positiva entre gestão da qualidade, competitividade e excelência em gestão.

A implantação de um sistema de gestão da qualidade possibilitam as organizações serem mais eficientes na gestão dos processos. Via metodologias de controle exercido nos processos, maiores quantidades de informações são captadas, facilitando a identificação de problemas em tempo hábil, evitando falhas, desperdícios e consequentemente minimizando reduções na produtividade.

Prajogo (2011) evidencia que as empresas implantam sistemas de gestão de qualidade, motivadas por razões internas, que podem ser a busca por melhoria nos processos, e produtos; ou por pressões externas, geralmente causadas por exigências do governo, de fornecedores ou de clientes.

Os motivos internos correspondem ao suprimento das necessidades de melhoria identificadas pela gestão da empresa, visando implantar um programa eficaz para garantir a 


\section{ReLAlnEP}

qualidade, a partir da documentação, rastreabilidade e o monitoramento, em todos os processos, produtos e serviços gerados pela organização, de forma a reduzir os erros, evitar o retrabalho, e melhorar a comunicação com o cliente (PRAJOGO, 2011).

As organizações orientadas por motivos externos, resolvem implantar a ISO 9000 ou outros sistemas de gestão de qualidade, como forma de melhorar a sua imagem e reputação no mercado, ou visando atender as necessidades de clientes ou fornecedores (PRAJOGO, 2011).

Porter (1980) afirma que as empresas são mais competitivas, quando adotam e estratégias de diferenciação, que permitem desenvolver características percebidas como importantes pelos clientes, que são capazes de tornar seus produtos ou serviços excelentes.Neste sentido, num mercado competitivo, as empresas que tenham um sistema de gestão de qualidade implantado, frequentemente revisto e adaptado, e que sejam certificadas, incrementam sua diferenciação perante as demais, acrescentando sua vantagem competitiva, pois são reconhecidas pelos clientes e fornecedores como capazes de atender suas expectativas.

Prajogo (2011) concorda que para que as empresas

produzam

melhoresresultados,detenham excelência em gestão e competitividade, não basta somente ter aderido a um sistema de gestão de qualidade. Entretando o autor considera esta adoção como "um bom ponto de partida".

Em resumo, a consolidação da competitividade propiciam as organizaçoes fidelizarem seus clientes, o que é fundamental para geração de resultados. No entanto se uma empresa realmente quer alcançar vantagens competitivas sustentaveis ela precisa promover a excelência em toda organização. Excelência encontrada nos sistemas avançados de gestão da qualidade (VIADA-STENGER ET AL, 2009).

\subsection{Indústria automobilística brasileira e suas concessionárias}

No Brasil, os últimos dados da Associação Nacional dos Fabricantes de Veículos Automotores, a ANFAVEA, entre os anos de 2002 e 2011 o mercado automotivo cresceu $145 \%$, com média anual superior a $10 \%$, enquanto a produção, embora em ritmo menor que o das vendas internas, expandiu-se $109 \%$ no período, média de $8,6 \%$ ao ano. Este mercado no ano de 2011 faturou US\$ 93.541.000 em veículos automotivos leves, com uma produção de 2.519.389 veículos leves, gerando 125.972 empregos diretos (ANFAVEA, 2012).

Até setembro de 2012, dados do Departamento Nacional de Trânsito, DENATRAM (2012), apontam que somente no estado do Rio Grande do Norte foram licenciados 3. 378.504 de veículos leves, destes 1.655.752 encontram-se na capital do estado. Para poder atender a esta demanda expressiva é preciso possuir redes de distribuição altamente capacitadas. Neste sentido observa-se a importância das concessionárias, organizações estas que precisam encontrar-se preparadas para atender 


\section{ReLAInEP}

ao público consumidor crescente, detentor de altos níveis de exigência e poderes de barganha, esta última por sua vez proporcionada pelas diversas opções de compra existentes no mercado.

Em todo país, são mais de 3500 concessionárias, filiadas à ANFAVEA, destas 42 encontram-se no estado do Rio Grande do
Norte, sendo 29 na capital do estado.

Das 29 concessionárias de veículos leves sediadas em Natal/RN, ambas possuem atuação global, sendo possível encontrar revendas autorizadas de 10 montadoras europeias, 05 norte americanas e14 asiáticas, como evidência a tabela 1 .

\section{TABELA 1: MONTADORAS COM CONCESSIONÁRIAS EM NATAL/RN}

\begin{tabular}{l|l}
\hline Montadora & Pais/Continente de Origem \\
\hline Audi & Alemanha / Europa \\
BMW & Alemanha / Europa \\
Chery & China / Ásia \\
Chevrolet & Estados Unidos / America do Norte \\
Chrysler & Estados Unidos / America do Norte \\
Citroen & França / Europa \\
Dodge & Estados Unidos / America do Norte \\
Effa Motors & China / Ásia \\
FIAT & Itália / Europa \\
Ford & Estados Unidos / America do Norte \\
Honda & Japão / Ásia \\
Hyundai & Coréia do Sul / Ásia \\
JAC Motors & China / Ásia \\
Jeep & Estados Unidos / America do Norte \\
Kia Motors & Coréia do Sul / Ásia \\
Land Rover & Inglaterra / Europa \\
Lifan & China / Ásia \\
Mahindra & Índia / Ásia \\
MINI & Inglaterra / Europa \\
Mitsubishi & Japão / Ásia \\
Nissan & Japão / Ásia \\
Peugeot & França / Europa \\
Renault & França / Europa \\
Ssangyoung & Coréia do Sul / Ásia \\
Suzuki & Japão / Ásia \\
Towner e Topic & China / Ásia \\
&
\end{tabular}




\begin{tabular}{ll} 
Toyota & Japão / Ásia \\
Volkswagen & Alemanha / Europa \\
Volvo & Suécia / Europa \\
\hline
\end{tabular}

Fonte: Elaborado pelos autores

\section{Metodologia de pesquisa}

Quanto à natureza, esta pesquisa é classificada como aplicada. Em relação aos objetivos, esta pesquisa é descritiva e exploratória. Quanto à abordagem, classifica-se como quantitativa utilizando-se o método Survey.

A seguinte técnica envolve a padronização de instrumentos de coleta de dados (questionários e entrevistas) que são aplicados diretamente às pessoas de uma população específica, cujo comportamento e características desejam-se conhecer. É adequado para testar hipóteses, modelos e proposições teoricamente fundamentados (FORZA, 2002).

Este estudo foi realizado com uma amostra de 22 concessionárias automotivas, o que corresponde a 75,8\% das concessionárias situadas em Natal/RN, capital do Estado do Rio Grande do Norte, Brasil, a fim de levantar o nível de adoção as práticas de qualidade. Buscou-se também identificar a existência sistemas de gestão da qualidade nessas organizações, possibilitando verificar a influência desses sistemas nos níveis de adoção as práticas de qualidade encontrada nas organizações.

A pesquisa aconteceu em duas etapas. A primeira correspondeu a pesquisa bibliográfica, na qual foi preciso rever a literatura existente e definir o escopo para a pesquisa, gerando produtos como a fundamentação teórica e identificação do pressuposto da pesquisa. A segunda correspondeu a fase exploratória e delimitação da pesquisa, na qual foi preciso elaborar e aplicar o instrumento de coleta e posteriormente executar o tratamento das informações, possibilitando a analise dos resultados e a dissertação das considerações finais.

$\mathrm{O}$ instrumento de coleta utilizado foi o questionário estruturado orientado por uma escala ordinal de concordância, do tipo Likert, de 5 pontos variando de 1 (mais negativo) a 5 (mais positivo) pontos, sendo: (1) muito ruim (2) ruim (3) regular (4) bom e (5) muito bom. A ferramenta para coleta de dados praticado nessa pesquisa originou-se a partir de uma adaptação do instrumento utilizado por Ilkay e Aslan (2011), o qual incorpora 24 indagações alocadas em 6 fatores constituintes das práticas da qualidade, descritos a seguir: 1 - Liderança da alta gerência, 2 - Orientação para o cliente, 3 - Sistema de qualidade: processos, 4 Recursos humanos, 5 - Relações com fornecedores e 6 - Controle e melhoria de processos.

$\mathrm{Na}$ fase de execução, os pesquisadores visitaram cada uma das 22 concessionárias requerendo o preenchimento do instrumento pelos "Gerentes Operacionais", entendendo 


\section{ReLAInEP}

que eles conhecem e gerenciam todo $\mathrm{o}$ processo de serviço prestado, estando aptos a prover as informações coerentes. Com os dados registrados, através do software Microsoft Excel, conseguiu-se gerar os gráficos utilizados para interpretação dos resultados, estes por sua vez calculados via uso do software estatístico livre "R", o qual forneceu tratamentos estatísticos necessários para identificar os níveis de adoção as práticas de qualidade, seja de forma geral, seja de forma isolada a cada fator.

\section{Resultados}

Os resultados demonstraram, em aspectos gerais, considerando todos os 6 fatores e 24 quesitos, que 20 concessionárias obtiveram nível de adoção as práticas de qualidade entre 4 "bom" e 5 "muito bom", sendo 7 com conceito "bom" e 13 com conceito "muito bom". Das 2 concessionárias restantes, uma obteve conceito 3 "regular" e a outra conceito 2 "ruim".

Em aspectos isolados, verificando cada fator e seus quesitos formadores, observamos que no primeiro item - liderança da alta gerência -, a maioria das concessionárias apontaram conceitos satisfatórios (Gráfico 1).

Quanto ao quesito 1 (na concessionária a alta gerência fornece recursos para a promoção de atividades relacionadas à qualidade), $86,3 \%$ das concessionárias indicaram notas positivas entre 4 e 5. Quanto ao quesito 2 (na concessionária existe uma política de qualidade desenvolvida pela alta gerência), $77,2 \%$ das concessionárias indicaram notas positivas entre 4 e 5. Quanto ao quesito 3 (na concessionária os objetivos da qualidade mensuráveis são estabelecidos com base na atividade desenvolvida por cada setor), novamente $77,2 \%$ das concessionárias indicaram notas positivas entre 4 e 5 . Por fim, quanto ao quesito 4 (na concessionária a alta gerência revê regularmente atividades relacionadas com a qualidade), $68,1 \%$ das concessionárias indicaram notas positivas entre 4 e 5 , e $27,7 \%$ indicaram nota 3 regular, sendo a maior frequência observada entre os conceitos 1, 2 e 3 em todo o fator.

Sobre o segundo fator "orientação ao cliente", a maioria das concessionárias apontaram novamente conceitos satisfatórios (Gráfico 2). 


\section{ReLAInEP}

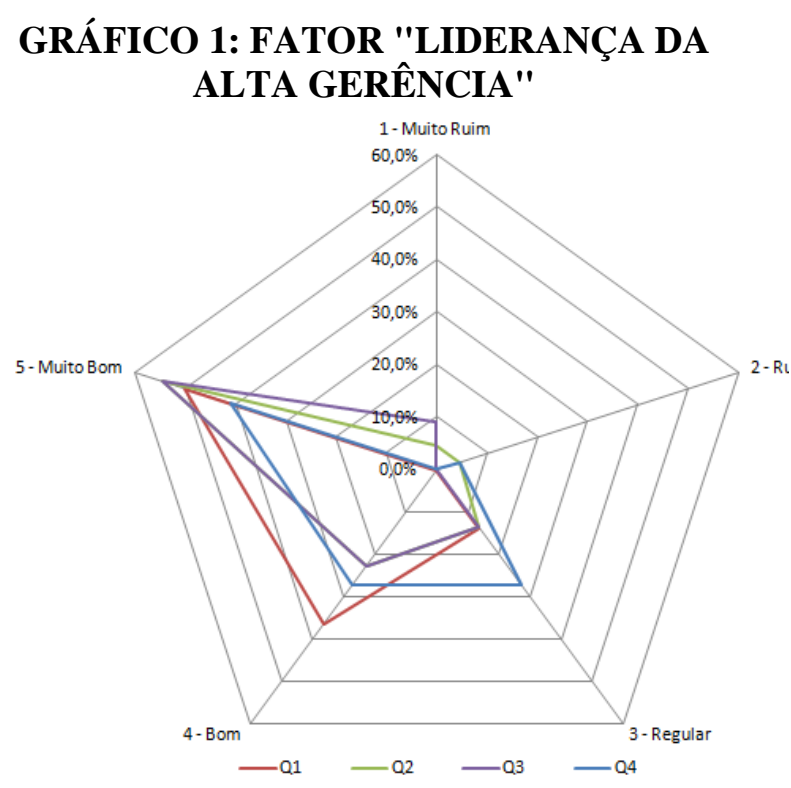

Fonte: Elaborado pelos autores
GRÁFICO 2: FATOR "ORIENTAÇÃO AO

CLIENTE"

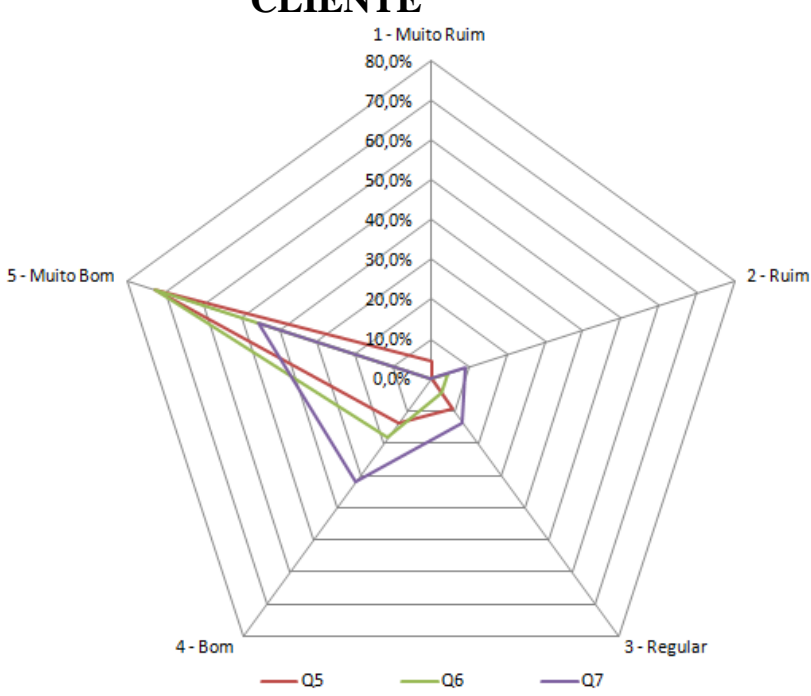

Fonte: Elaborado pelos autores

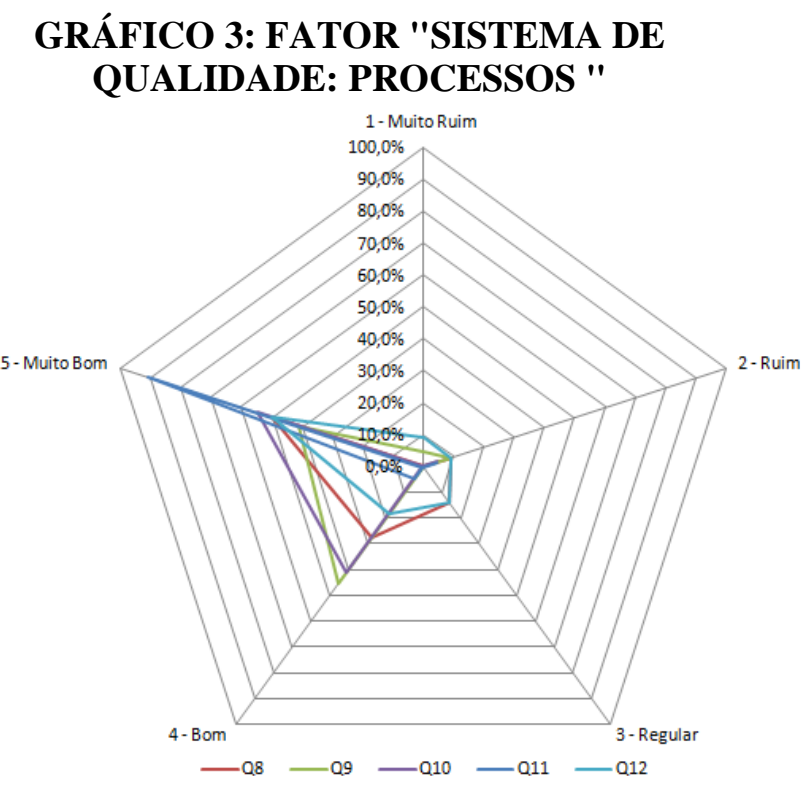

Fonte: Elaborado pelos autores
Quanto ao quesito 5 (na concessionária pesquisam-se informações sobre a percepção dos clientes quanto aos seus requisitos/pretensões e necessidades), $86,3 \%$ das concessionárias indicaram notas positivas entre 4 e 5. Quanto ao quesito 6 (a concessionária analisa os dados informativos fornecidos pelos clientes), $90,1 \%$ das concessionárias indicaram notas positivas entre 4 e 5. Quanto ao quesito 7 (na concessionária os dados informativos fornecidos pelos clientes são computados e utilizados para a melhoria dos produtos e serviços vendidos), $77,2 \%$ das concessionárias indicaram notas positivas entre 4 e 5 e 13,6\% indicaram nota 3 regular, sendo a maior frequência observada entre os conceitos 1,2 e 3 , em todo o fator.

Sobre o terceiro fator "sistema de qualidade: processos", o gráfico 3 a seguir aponta novamente conceitos satisfatórios. 


\section{ReLAInEP}

\section{GRÁFICO 4: FATOR "RECURSOS}

HUMANOS"

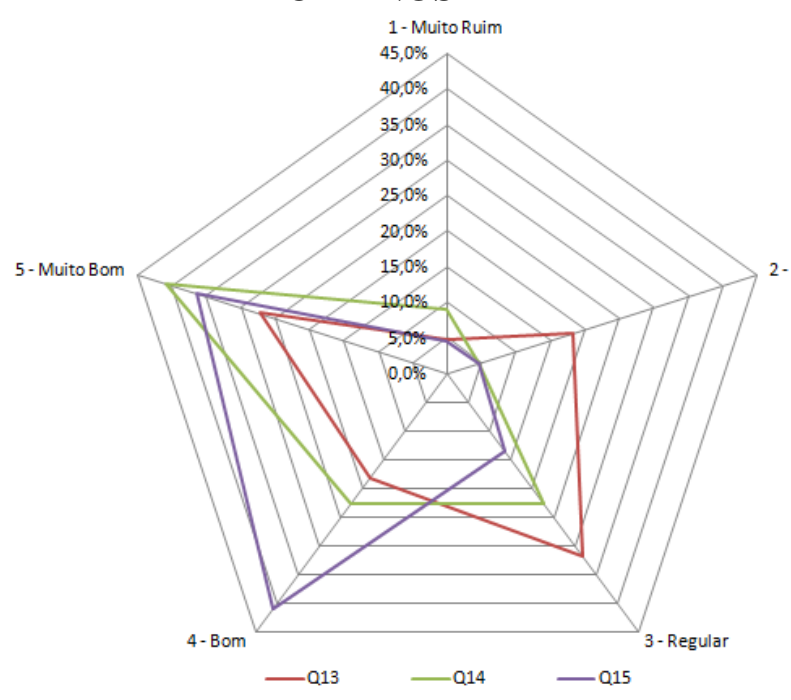

Fonte: Elaborado pelos autores

Quanto ao quesito 13 (na concessionária os cargos e funções são claramente definidos) mesmo com 45,4\% das concessionárias indicarem notas positivas entre 4 e 5, 31,8\% indicaram nota 3 regular e $22,6 \%$ notas negativas entre 1 e 2 , consolidando esse quesito com a maior frequência de rejeição apontada em todo estudo. Quanto ao quesito 14 (na concessionária a autoridade e responsabilidade dos funcionários estão claramente definidas), $63,4 \%$ das concessionárias indicaram notas positivas entre 4 e 5. Quanto ao quesito 15 (na concessionária os funcionários empregados tem nível de qualificação profissional suficiente para contribuir no alcance dos objetivos de qualidade), $\quad 77,2 \%$ das concessionárias indicaram notas positivas entre 4 e 5 .

Sobre o quinto fator "relações com fornecedores", o gráfico 5 a seguir aponta novamente conceitos satisfatórios.

\section{GRÁFICO 5: FATOR "RELAÇÕES COM FORNECEDORES"}

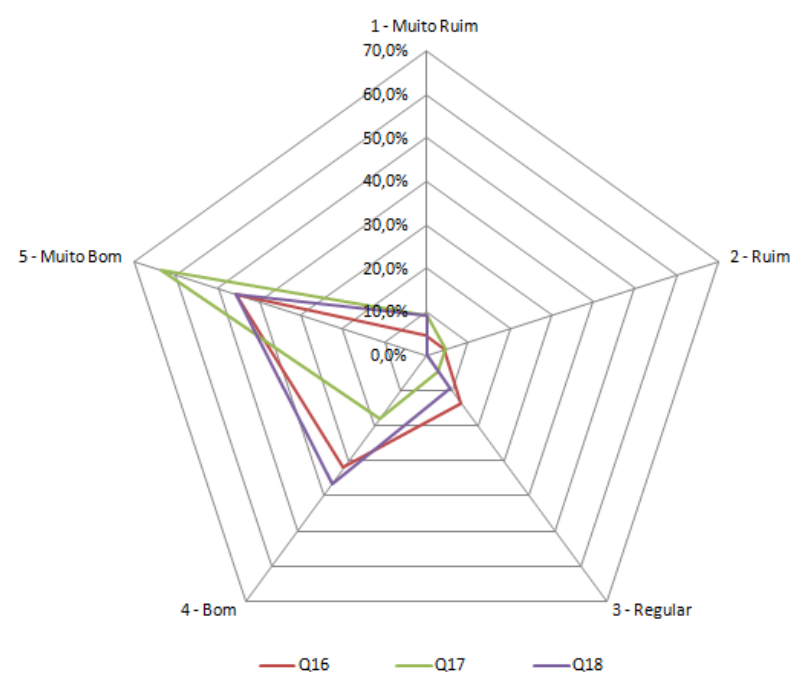

Fonte: Elaborado pelos autores

Quanto ao quesito 16 (na concessionária os critérios para seleção e avaliação dos fornecedores são determinados), $77,2 \%$ das concessionárias indicaram notas positivas entre 4 e 5 e 13,6\% indicaram nota 3 regular, sendo a maior frequência observada entre os conceitos 1, 2 e 3 em todo o fator. Quanto ao quesito 17 (na concessionária os critérios para compra de suprimentos são determinados), $81,8 \%$ das concessionárias indicaram notas positivas entre 4 e 5 . Quanto ao quesito 18 (na concessionária é realizada inspeção e controle dos suprimentos recebidos), novamente $81,8 \%$ das concessionárias indicaram notas positivas entre 4 e 5.

Sobre o sexto fator "controle e melhoria de processos", o gráfico 6 a seguir aponta novamente conceitos satisfatórios. 
GRÁFICO 6: FATOR "CONTROLE E MELHORIA DE PROCESSOS"

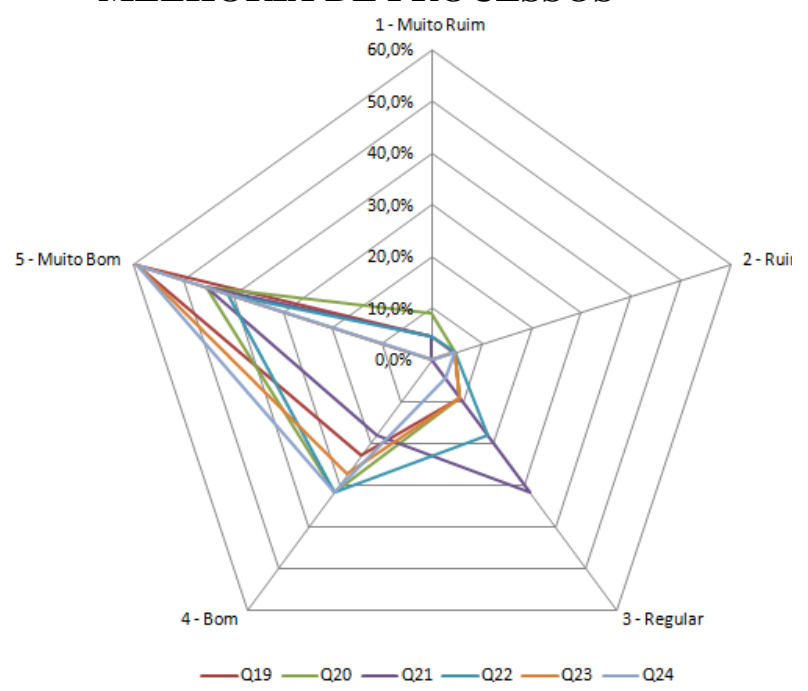

Fonte: Elaborado pelos autores

Quanto ao quesito 19 (a concessionária possui ferramentas para analise e medição dos processos), $81,8 \%$ das concessionárias indicaram notas positivas entre 4 e 5 . Quanto ao quesito 20 (na concessionária as ferramentas de medição são ajustadas periodicamente), $77,2 \%$ das concessionárias indicaram notas positivas entre 4 e 5 . Quanto ao quesito 21 (na concessionária as características dos produtos e serviços são medidas provendo sua conformidade), $63,6 \%$ das concessionárias indicaram notas positivas entre 4 e 5 e $31,8 \%$ indicaram nota 3 regular, sendo a maior frequência observada entre os conceitos 1, 2 e 3, em todo o fator. Quanto ao quesito 22 (na concessionária os dados extraídos das medições são prontamente analisados), $\quad 72,7 \%$ das concessionárias indicaram notas positivas entre 4 e 5 . Quanto ao quesito 23 (na concessionária as informações extraídas dos dados coletados são utilizadas para a melhoria continua da qualidade), $\quad 86,3 \%$ das concessionárias indicaram notas positivas entre 4 e 5 . Quanto ao quesito 24 (na concessionária ações corretivas e preventivas são realizadas), 90,3\% das concessionárias indicaram notas positivas entre 4 e 5.

Sobre a relação entre nível de adoção as práticas de qualidade com utilização de sistemas de gestão da qualidade, das 22 concessionárias verificadas, 17 apontaram adotar sistemas de gestão da qualidade, dessas, em aspectos gerais, 11 mostraram possuir nível 5 "muito bom" nas adoções as práticas de qualidade e 6 mostraram nível 4 "bom". As 5 concessionárias restantes, que citaram não possuir algum sistema de gestão da qualidade, 2 mostraram possuir nível 5 "muito bom" nas adoções as práticas de qualidade, 1 nível 4 "bom", 1 nível 3 "regular" e somente 1 com nível 2 "ruim".

\section{Conclusões}

Em relação ao nível de adoção as práticas de qualidade, as concessionárias da capital do estado do Rio Grande do Norte, mostraram em sua maioria, níveis de qualidade satisfatórios, condizentes com organizações que reconhecem o mercado competitivo na qual está inserida, ou seja, as concessionárias demonstraram entender que as práticas de qualidade fornecem capacidade de melhoria aos seus processos e produtos, possibilitando suprir as necessidades dos clientes de forma consistente, promovendo sua força competitiva. 
A pesquisa observou concessionárias com alta direção comprometida a desenvolver e aplicar políticas de qualidade, concentrada em identificar as pretensões e analisar as necessidades dos clientes, empenhada na melhoria processual através da definição de limites de variabilidade, orientada a seleção de fornecedores e determinada a garantir conformidade de seus produtos.

Mesmo praticando todos esses esforços críticos as gerações da qualidade, as concessionárias abordadas nesse estudo, em sua maioria, precisam melhorar a forma com que aplicam seus recursos humanos, principalmente na definição dos cargos e funções. Essas atribuições precisam estar claramente definidas, para que não ocorra nenhum desvio de função, e este em algum momento resulte na condução de uma tarefa por um colaborador que não foi devidamente capacitado a executála, comprometendo a qualidade do serviço prestado e consequentemente levar a insatisfação do cliente.

Em relação à utilização de sistemas de gestão da qualidade e sua influencia nos níveis encontrados de adoção as práticas de qualidade, a pesquisa evidenciou que aplicar sistemas de qualidade propicia alta possibilidade de obter níveis máximos de adoção. Entretanto, a pesquisa mostrou que não necessariamente precisam-se implantar sistemas de gestão de qualidade para obter resultados máximos nos níveis de adoção, existindo a possibilidade de promover a qualidade organizacional sem aplicações sistemáticas.
É importante ressaltar que o sistema de qualidade utilizado nas concessionárias abordadas pela pesquisa segue orientações globais das montadoras, sendo na maioria das vezes acompanhadas por consultorias designadas por elas. Essa realidade, confrontada com todos os resultados obtidos pela pesquisa, faz acreditar que não só as concessionárias de Natal/RN, bem como a maioria das concessionárias brasileiras estão prontas e capacitadas a oferecer produtos e serviços de qualidade mundial.

\section{Referências}

ABNT, ASSOCIAÇÃO BRASILEIRA DE NORMAS TÉCNICAS. ISO 9001:2008 Sistemas de Gestão da Qualidade Requisitos. Rio de janeiro. 2008.

ANEF, ASSOCIAÇÃO NACIONAL DAS EMPRESAS FINANCEIRAS DAS MONTADORAS. Estimativa financeira anual para financiamento automotivo no ano de 2012. Disponível: http://www.anef.com.br/, acesso em 23 Nov, 2012.

ANFAVEA, ASSOCIAÇÃO NACIONAL DOS FABRICANTES DE VEÍCULOS AUTOMOTORES. Anuário da Indústria Automobilística Brasileira. São Paulo. 2012

ANN C. P., AYMAN B. A., YOSHIKI M. Quality management practices and competitive performance: Empirical evidence from Japanese manufacturing companies. Int. J. Production Economics 133, 518-529. 2011.

BAIRD, K. HU, J, K, REEVE, R. The relationships between organizational culture, total quality management practices and operational performance. International Journal of Operations \& Production Management, Vol. 31 Iss: 7 pp. 789 - 814. 2011.

CROSBY, P. B. Qualidade falada a sério. São Paulo: McGraw-Hill. 1990. 
DEMING, W. E. Qualidade: A Revolução da Administração. Rio de Janeiro: Marques Saraiva. 1990.

DENATRAN, DEPARTAMENTO NACIONAL DE TRÂNSITO. Frota 2011. Disponível em: <http://www.denatran.gov.br/frota.htm> Acesso em 16 Set, 2012.

DYNAMICS, J. Números da Indústria automobilística mundial no ano de 2012. Disponível:

http://www.jato.com/Brazil/Pages/default.aspx, Acesso em 23 Nov, 2012.

FOLHA DE SÃO PAULO. Em meio à crise mundial, agência $S \& P$ eleva nota de crédito do Brasil. Disponível em: <http://wwwl.folha.uol.com.br/poder/10080 84-em-meio-a-crise-mundial-agencia-sp-elevanota-de-credito-do-brasil.shtml> Acesso em: 19 Nov, 2011.

FORZA, C. Survey research in operational management: a process-based perspective. International Journal of Operations \& Productions Management, v. 22, n. 2, 2002.

FUENTES-FUENTES, M. M., LLORENSMONTES, F. J. , MOLINA-FERNANDES, L. M., ALBACETE-SAEZ, CARLOS A. Environment-quality management co alignment across industrial contexts: An empirical investigation of performance implications. Industrial Marketing Management 40, 730-742. 2011.

GARVIN, D. A. Gerenciando a qualidade: a visão estratégica e competitiva. Rio de Janeiro: Qualitymark. 1992.

ILKAY, M.S.; ASLAN, M. The effect of the ISO 9001 quality management system on the performance of SMEs. International Journal of Quality \& Reliability Management, Vol. 29 Iss: 7 pp. 753 - 778. 2011.

IRANI, Z.; BESKESE, A.; LOVE, P.E.D. Total quality management and corporate culture: constructs of organizational excellence. Technovation 24, pp. 643-650. 2004.

JURAN, J. M. Planejando para a qualidade. São Paulo: Pioneira. 1990.
LEE, D.H. Implementation of quality programs in health care organizations. Service Business. vol. 6, issue 3, p. 387 - 404, 2012.

MDIC, MINISTÉRIO DO DESENVOLVIMENTO, INDÚSTRIA E COMÉRCIO EXTERIOR. Relatório de gestão 2011. Disponível: <http://www.mdic.gov.br/arquivos/dwnl_1343238 831.pd† Acesso em 23 Nov, 2012.

PORTER, M.E. Competitive Strategy: Techniques for Analyzing Industries and Competitors. Free Press, New York. 1980.

POWELL, T. Total quality management as competitive advantage: a review and empirical study. Strat. Manage J 16(1): 1537. 1995.

PRAJOGO, D. I. The roles of firms motives in affecting the outcomes of ISO 9000 adoption. International Journal of Operations \& Production Management, Vol. 31 Iss: 1 pp. 78 - 100. 2011.

PRAJOGO, D.I, SOHAL, A.S. The relationship between organization strategy, total quality management (TQM), and organization performance--the mediating role of TQM. European Journal of Operational Research 168, 35-50. 2006.

SAMPAIO P., SARAIVA P., RODRIGUES A. G. ISO 9001 certification research: questions, answers and approaches. International Journal of Quality \& Reliability Management, Vol. 26 Iss: 1 pp. 38 - 58. 2009.

SLACK, N.; CHAMBERS, S.; JOHNSTON, R. Administração da Produção. $2^{a}$ ed.: São Paulo, Atlas. 2002

SRIVASTAV, A. K. Impact of ISO 9000 implementation on the organization. International Journal of Quality \& Reliability Management, Vol. 27 Iss: 4 pp. 438 450. 2010.

VIADA-STENGER, M.C.; BALBASTREBENAVENT, F.; REDONDO-CANO, A.M. The implementation of a quality management system based on the $Q$ tourist quality standard. The case of hotel sector. Service Business vol. 4, issue 3-4, p. 177 196, 2010. 